\title{
Artificial disc replacement versus fusion in patients with cervical degenerative disc disease and radiculopathy: a randomized controlled trial with 5-year outcomes
}

\author{
Anna MacDowall, MD, PhD, ${ }^{1}$ Nuno Canto Moreira, MD, PhD, ${ }^{2}$ Catarina Marques, MD, ${ }^{1}$ \\ Martin Skeppholm, MD, PhD, ${ }^{3,4}$ Lars Lindhagen, ${ }^{5}$ Yohan Robinson, MD, PhD, ${ }^{1}$ \\ Håkan Löfgren, MD, PhD, ${ }^{6}$ Karl Michaëlsson, MD, PhD, ${ }^{1}$ and Claes Olerud, MD, PhD ${ }^{1}$ \\ 'Department of Surgical Sciences, Uppsala University, Uppsala; ${ }^{2}$ Department of Clinical Neuroscience (CNS), K8, Karolinska

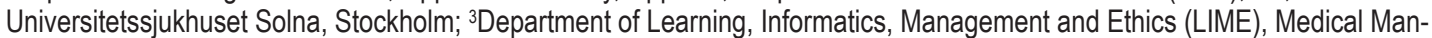 \\ agement Center, Health Economics and Health Evaluation Research Group, Karolinska Institutet, Stockholm; ${ }^{4}$ Center for Spine \\ Surgery in Stockholm, Sophiahemmets Sjukhus, Stockholm; ${ }^{5}$ Uppsala Clinical Research Center, Uppsala University, Uppsala; \\ and ${ }^{6}$ Department of Neuro-Orthopaedic Center, Ryhov, Jönköping, Sweden
}

\begin{abstract}
OBJECTIVE The method of artificial disc replacement (ADR) has been developed as an alternative treatment to fusion surgery after decompression for cervical degenerative disc disease (DDD) with radiculopathy. Preserving the motion of ADR devices aims to prevent immobilization side effects such as adjacent-segment pathology (ASP). However, longterm follow-up evaluations using MRI are needed to investigate if this intent is achieved.

METHODS The authors performed a randomized controlled trial with 153 patients (mean age 47 years) undergoing surgery for cervical radiculopathy. Eighty-three patients received an ADR and 70 patients underwent fusion surgery. Outcomes after 5 years were assessed using patient-reported outcome measures using the Neck Disability Index (NDI) score as the primary outcome; motion preservation and heterotopic ossification by radiography; ASP by MRI; and secondary surgical procedures.

RESULTS Scores on the NDI were approximately halved in both groups: the mean score after 5 years was $36(95 \%$ confidence interval [Cl] 31-41) in the ADR group and $32(95 \% \mathrm{Cl} 27-38)$ in the fusion group $(p=0.48)$. There were no other significant differences between the groups in six other patient-related outcome measures. Fifty-four percent of the patients in the ADR group preserved motion at the operated cervical level and $25 \%$ of the ADRs were spontaneously fused. Seventeen ADR patients $(21 \%)$ and 7 fusion patients $(10 \%)$ underwent secondary surgery $(p=0.11)$, with 5 patients in each group due to clinical ASP.
\end{abstract}

CONCLUSIONS In patients with cervical DDD and radiculopathy decompression as well as ADR, surgery did not result in better clinical or radiological outcomes after 5 years compared with decompression and fusion surgery.

Clinical trial registration no.: 44347115 (ISRCTN).

https://thejns.org/doi/abs/10.3171/2018.9.SPINE18659

KEYWORDS artificial disc replacement; treatment outcome; Neck Disability Index; cervical radiculopathy; adjacent-segment pathology

$\mathrm{D}$ EGENERATIVE changes in the cervical spine such as disc herniation and osteophyte formation may narrow the root canal of the nerve causing radiating pain. Hence, the lower cervical segments are most frequently affected, with pain radiating from the neck to the shoulder, arm, or hand..$^{2}$ Anterior cervical decompression and fusion has been the gold standard treatment with more than 100,000 patients each year receiving such surgery in the US. ${ }^{22}$ Hilibrand et al. reported on the development of adjacent-segment pathology (ASP) 10 years after fusion surgery and different devices of artificial disc replacement (ADR) have been developed since, as an alternative ap-

ABBREVIATIONS ADR = artificial disc replacement; $\mathrm{ASP}=$ adjacent-segment pathology; $\mathrm{CASP}=$ clinical $\mathrm{ASP} ; \mathrm{Cl}=\mathrm{confidence}$ interval; $\mathrm{DDD}=\mathrm{degenerative} \mathrm{disc} \mathrm{disease;}$ DSQ = Dysphagia Short Questionnaire; HADS = Hospital Anxiety and Depression Scale; HADS-a = HADS-anxiety; HADS-d = HADS-depression; HO = heterotopic ossification; HR = hazard ratio; IDE = investigational device exemption; ITT = intention to treat; MCID = minimum clinically important difference; NDI = Neck Disability Index; NSAID = nonsteroidal antiinflammatory drug; RASP = radiographic ASP; VAS = visual analog scale.

SUBMITTED May 23, 2018. ACCEPTED September 5, 2018.

INCLUDE WHEN CITING Published online January 11, 2019; DOI: 10.3171/2018.9.SPINE18659. 
proach. ${ }^{12}$ ADR is intended to preserve motion on the index level to prevent development of ASP, ${ }^{12}$ but such benefit is not fully realized in practice. ${ }^{23}$

Several nonblinded investigational device exemption (IDE) studies have shown clinical noninferiority when comparing ADR devices with fusion surgery. ${ }^{3,8,11,20,21,25,27}$ Only one 2-year clinical trial with blinding of patients after the procedure has been conducted. The results of that study were in favor of fusion surgery. ${ }^{34}$ Complications after ADR surgery occur, including spontaneous fusion and loosening. ${ }^{6,14,33,38}$ None of the larger open-label randomized controlled trials had long-term follow-up with MRI. Hence, there are still insufficient data to support the view that ADR devices succeed in preventing ASP.

The primary aim of this study was to compare whether an ADR device resulted in better 5-year clinical outcome (as measured by the Neck Disability Index [NDI]) than fusion surgery after anterior decompression in patients who underwent surgery for cervical degenerative disc disease (DDD) and radiculopathy. Secondary outcomes were the EQ-5D and pain scores; tertiary outcomes were secondary surgery and assessment of motion and ASP.

\section{Methods \\ Trial Design}

This trial has been described previously, reporting the 2-year follow-up ${ }^{29}$ and the predictors to 5 -year outcomes. ${ }^{17}$ Briefly, we conducted a multicenter randomized clinical superiority trial in which patients with cervical radiculopathy were randomly assigned to undergo either unconstrained ADR using the Discover artificial disc (DePuy Spine, Johnson \& Johnson), or fusion using an autologous iliac crest graft and plate after decompression. We enrolled patients with cervical radiculopathy who were 25-60 years old and who met the following inclusion criteria: symptoms of radiating arm pain with duration of at least 3 months, correlating findings on MRI at one or two cervical levels, eligible for both treatments, and the ability to understand and read Swedish. ${ }^{29}$ Enrollment of patients took place at 3 Swedish study centers between 2007 and 2011.

Exclusion criteria were: previous cervical spine surgery, more than 2 cervical levels requiring treatment, severe facet arthropathy, symptoms or marked radiological signs of myelopathy, drug abuse, dementia or expected low compliance, cervical malformation or marked instability, history of severe cervical trauma, pregnancy, rheumatoid arthritis, malignancy, active infection or other systemic disease, and known allergy to implant material or to nonsteroidal antiinflammatory drugs (NSAIDs).

After surgical exposure and decompression were completed, simple randomization without blocks was performed using a closed-envelope technique. Hence, both patient and surgeon were blinded until decompression was completed and instruments for both the ADR and fusion were prepared in the operating room. Surgery was performed with a standard anterior approach according to Smith and Robinson. ${ }^{30}$ The affected nerve was decompressed, which included removal of the posterior longitudinal ligament of the affected side and, if needed, the uncovertebral joints. In the patients who were then ran- domized to receive the ADR, further preparations and actions to complete the surgery were made according to the company guidelines. ${ }^{9}$ In the fusion group, a tricortical bone graft from the iliac crest was used for reconstruction along with a titanium plate of the surgeon's preference. To prevent heterotopic ossification (HO), patients in the ADR group were treated with NSAIDs for 10 days postoperatively; otherwise, the postoperative regime was the same in both groups. No collar or restrictions were used in either group. All participating surgeons were highly experienced in performing both trial interventions.

\section{Data Collection and Outcomes}

Baseline characteristic questionnaires were distributed to the patients before surgery and postal-validated patientreported outcome questionnaires were distributed to the patients before surgery and 4 weeks, 3 months, and 1, 2, and 5 years postoperatively.

The primary outcome measure (the NDI score) is a 10item self-administered questionnaire measuring disability in patients with neck pain. The questions measure daily activities (e.g., the ability to dress, lift heavy objects, read, work, drive a car, sleep, and perform leisure time activities) as well as concentration abilities and the severity of pain and headache. Each item is scored from 0 to 5. The maximum score is 50 points, indicating severe disability, and the minimum score is 0 , indicating no disability. The score we used was transformed to a percentage (score out of 100) by doubling the total score (range 0\%-100\%). The minimum clinically important difference (MCID) is $15-17.3 .5,24,39$

Secondary outcomes were the EQ-5D (range from 0 to 1 , with higher scores reflecting better quality of life) $)^{31}$ and visual analog scales (VASs) for neck and arm pain ${ }^{18}$ (range 0-100 mm), with higher scores indicating more severe pain). The MCID is $21 \mathrm{~mm}$ for VAS-neck and $29 \mathrm{~mm}$ for VAS-arm. ${ }^{18}$

We also assessed dysphagia using the Dysphagia Short Questionnaire (DSQ, ${ }^{28}$ range $0-18$, with higher values representing more severe symptoms). The Hospital Anxiety and Depression Scale $\left(\mathrm{HADS}^{40}\right)$ was used to assess the prevalence of anxiety (HADS-a) and depression (HADSd). Scores for each subscale range from 0 to 21 , with a total score of 42.

To investigate tertiary outcomes, all patients were summoned to a doctor's appointment for neurological examination 5 years after surgery. This neurological examination was performed to follow up on reoperations and new radiculopathy. A spine surgeon (A.M.) not involved in the surgery procedures performed the examination, which included tests of reflexes, sensory function, and muscle strength in the cervical dermatomes and myotomes.

Plain flexion-extension radiographs were performed preoperatively and after 1,2 , and 5 years to evaluate range of motion in the index level by measuring Cobb angles on the functional spinal unit. ${ }^{13}$ We defined motion on one level to be a $5^{\circ}$ difference or more between flexion and extension radiographs. ${ }^{35}$ A neurosurgeon (C.M.) not involved in the original study evaluated all radiographs. We applied the Mehren/Suchomel modification of the McAfee classification to classify the appearance of $\mathrm{HO}$. 
MR and T1- and T2-weighted images in sagittal and axial planes were executed in connection with the doctor's appointment at 5 years, on all participating patients, whether they had symptoms or not. Facet arthropathy and disc degeneration on adjacent segments were detected by MRI before and 5 years after surgery. Classification was performed by a neuroradiologist (N.C.M.) according to 5-level grading schemes: Walraevens et al. ${ }^{36}$ for facet arthropathy, and Miyazaki et al. ${ }^{19}$ for ASP. Clinical ASP (CASP) was defined as clinical symptoms and signs that occurred at the adjacent segment, consistent with degenerative changes on MRI at the 5-year follow-up. ${ }^{2}$ CASP was defined as severe if nonoperative treatment had failed and new surgery was indicated. Otherwise, if nonoperative treatment were sufficient, CASP was defined as mild. Radiographic ASP (RASP) was defined as degenerative changes at the adjacent segment on MRI without the patient reporting any discomfort and with normal neurological examination results.

\section{Trial Oversight}

The trial was approved by the local Swedish ethics review boards and all participants provided oral and written informed consent. No institution or company had a role in the data analysis, preparation of the manuscript, or the decision to submit the manuscript for publication. The study was registered at ISRCTN (registration no. 44347115).

\section{Statistical Analysis}

We calculated that a minimum of 102 patients would be required for a superiority trial to have $80 \%$ power with $\alpha=0.05$ to detect an MCID in the NDI score of at least $10^{16,26,29}$ between the treatment groups. To make up for crossovers and noncompliance, the final sample included 153 patients.

Patient-related outcome measures were primarily analyzed as intention to treat (ITT) and included all randomized patients. Missing values were imputed with multiple imputation using chained equations as implemented in the $\mathrm{R}$ package MICE ${ }^{37}$ with 20 iterations. Using ANCOVA, we calculated mean 5-year outcome values for each treatment group adjusted for baseline values of the outcome. The mean difference of the 5-year values between the groups is also presented with a $95 \%$ confidence interval (CI). A positive mean difference corresponds to higher values for $\mathrm{ADR}$ (compared with fusion).

The tertiary outcome analyses were based on available cases. We analyzed time to revision surgery by KaplanMeier plots and estimated hazard ratios (HRs) of having secondary surgery after ADR compared with fusion by Cox regression, with calendar time as the basic time scale. Men and women were analyzed separately to investigate whether there were sex differences. The proportional hazard assumptions were confirmed graphically by Schoenfeld residuals.

We compared the proportion of HOs in women and men and the proportion of facet arthropathy at baseline and at 5 years postsurgery. Furthermore, we compared the prevalence of CASP between different subgroups: ADR versus fusion, as well as mobile ADR versus fusion. The development of RASP, measured as $\Delta$ MRI grade between
TABLE 1. Patient demographics at baseline

\begin{tabular}{lcc}
\hline \multicolumn{1}{c}{ Patient Characteristics } & $\begin{array}{c}\text { ADR Group } \\
(\mathrm{n}=83)\end{array}$ & $\begin{array}{c}\text { Fusion Group } \\
(\mathrm{n}=70)\end{array}$ \\
\hline Men/women & $42 / 41$ & $33 / 37$ \\
\hline Mean age (SD), yrs & $46.9(6.8)$ & $47.0(6.9)$ \\
\hline Smokers, $\mathrm{n}(\%)$ & $26(32)$ & $21(31)$ \\
\hline Mean weight (SD), $\mathrm{kg}$ & $79(18)$ & $78(14)$ \\
\hline Mean BMI & 26 & 26 \\
\hline Pension, $\mathrm{n}(\%)$ & $1(1)$ & $0(0)$ \\
\hline Unemployed, $\mathrm{n}(\%)$ & $8(10)$ & $10(15)$ \\
\hline Sick leave/disability pension, $\mathrm{n}(\%)$ & $56(68)$ & $44(67)$ \\
\hline Heavy work, $\mathrm{n}(\%)$ & $72(88)$ & $54(82)$ \\
\hline Neck pain duration, $\mathrm{n}(\%)$ & & \\
\hline$<3$ mos & $2(2)$ & $1(1)$ \\
\hline 3-12 mos & $15(18)$ & $19(27)$ \\
\hline 1-2 yrs & $20(24)$ & $20(29)$ \\
\hline$>2$ yrs & $40(48)$ & $29(41)$ \\
\hline Arm pain duration, $\mathrm{n}(\%)$ & & \\
\hline$<3$ mos & $3(4)$ & $3(4)$ \\
\hline 3-12 mos & $21(25)$ & $24(34)$ \\
\hline 1-2 yrs & $31(37)$ & $19(27)$ \\
\hline$>2$ yrs & $26(31)$ & $24(34)$ \\
\hline Regular exercise, $\mathrm{n}(\%)$ & $35(42)$ & $18(26)$ \\
\hline Mean HADS-d score $\pm \mathrm{SD}$ & $5.0 \pm 3.5$ & $4.7 \pm 3.7$ \\
\hline Mean HADS-a score $\pm \mathrm{SD}$ & $7.0 \pm 4.2$ & $7.0 \pm 4.1$ \\
\hline Mean NDI score $\pm \mathrm{SD}$ & $63.9 \pm 16.6$ & $61.5 \pm 14.5$ \\
\hline Mean EQ-5D \pm SD & $0.4 \pm 0.3$ & $0.5 \pm 0.3$ \\
\hline Mean VAS-neck $\pm \mathrm{SD}$ & $57.6 \pm 26.4$ & $58.2 \pm 23.1$ \\
\hline Mean VAS-arm $\pm \mathrm{SD}$ & $57.1 \pm 27.5$ & $56.9 \pm 23.0$ \\
\hline
\end{tabular}

preoperative and 5-year MRI, was compared between the ADR and fusion groups.

All statistical analyses were performed in $\mathrm{R}$ (version 3.1.0; http://www.R-project.org/; R Foundation for Statistical Computing).

\section{Results}

Of the 153 patients, 83 were randomized to ADR, and 70 to fusion surgery, with a mean follow-up period of 66 months (range 57-77 months). The mean age was 47 years (range 31-62 years), 78 patients were women, and 75 were men (Table 1). The 5-year follow-up of the primary outcome was completed in all patients but 9 in each group (Fig. 1). The most common levels at which patients received surgical treatment were C5-6 $(\mathrm{n}=50,33 \%), \mathrm{C} 6-7$ $(n=50,33 \%)$, or both (i.e., 2-level surgery, C5-7; $n=44$, $29 \%) .{ }^{17}$

\section{Outcomes at 5 Years \\ ITT Analysis}

The ADR group improved in NDI from 64 (95\% CI 60.4-67.6) to 36 (95\% CI 31.2-40.8) and the fusion group from 61 (95\% CI 57.9-65.0) to 32 (95\% CI 26.6-37.9; Fig. 


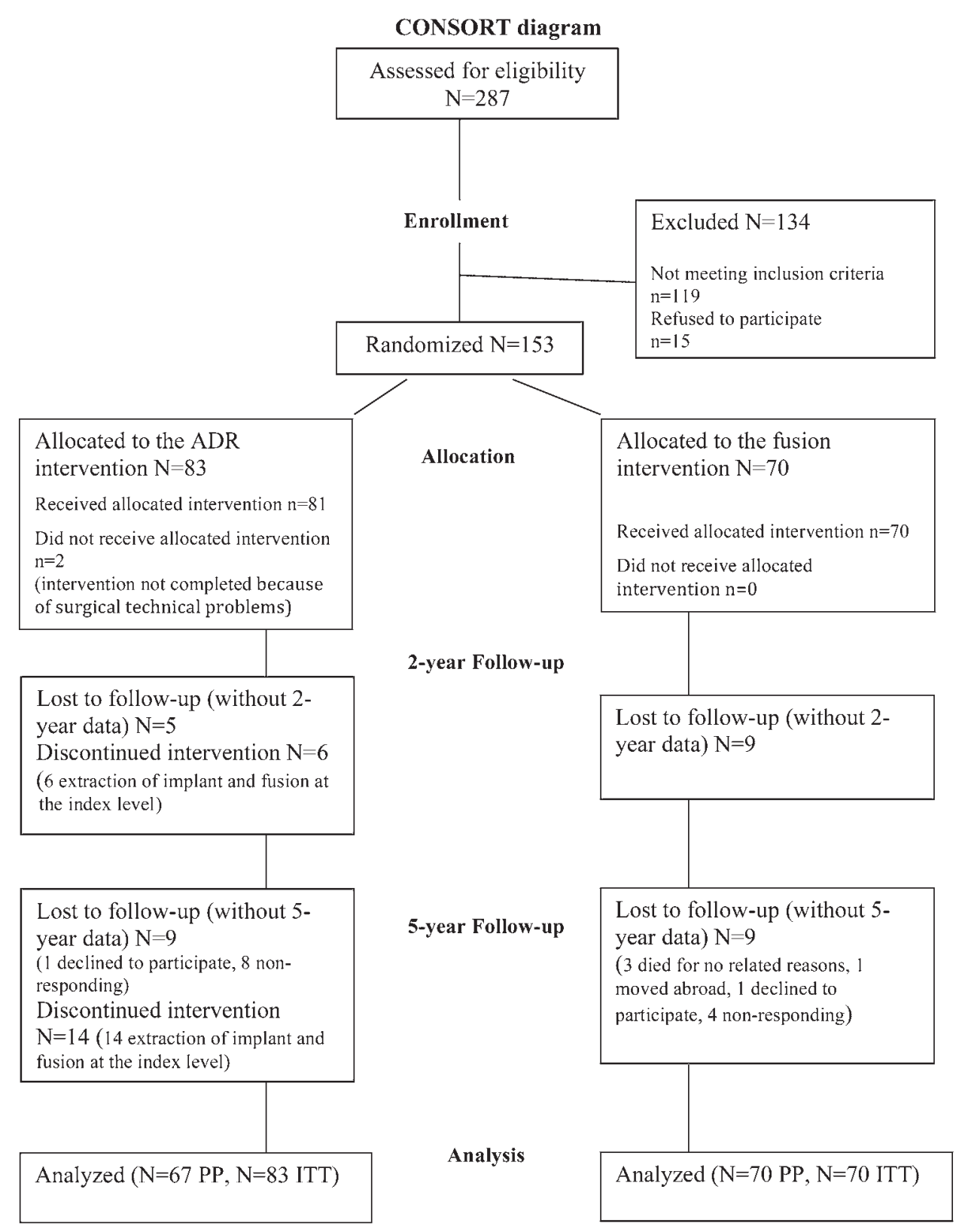

FIG. 1. Consort diagram. PP = per-protocol.

2), with a mean difference of $2.5(95 \% \mathrm{CI}-4.5$ to $9.4 ; \mathrm{p}=$ 0.48; Table 2).

The EQ-5D revealed no mean differences between groups $(-0.07,95 \% \mathrm{CI}-0.19$ to 0.05$)$, nor did the VASneck $(-2.3,95 \%$ CI -11.3 to 6.7$)$, VAS-arm $(0.2,95 \%$ CI -8.3 to 8.8$)$, or DSQ $(-0.7,95 \%$ CI -1.4 to 0.1 ; Table 2$)$.

\section{Per-Protocol Analysis}

The results of the per-protocol analysis were similar to those of the ITT analysis. There was, however, a modest difference in dysphagia in favor of ADR (mean DSQ -0.8, $95 \% \mathrm{CI}-1.6$ to $-0.0 ; \mathrm{p}=0.045$ ), but the overall scores at the 5-year follow-up were generally low in both groups (mean score in the ADR group $=1.5$, mean score in the fusion group $=2.3$; Table 3).

\section{Secondary Surgery}

Seventeen patients in the ADR group and 7 in the fusion group underwent secondary surgery $(\mathrm{p}=0.11$; Fig. 3 ), but the higher risk in the ADR group was confined to women (HR 10.5, 95\% CI 1.4-80.9); the HR in men was 0.55 (95\% CI $0.17-1.83$ ), with a $p$ value for interaction of 0.014. Reoperations were primarily attributed to loosening and subsidence $(n=14$; Table 4$)$.

Preserved Motion and Development of $\mathrm{HO}$ and Facet Arthropathy

In the ADR group there were 22 radiographs lost to follow-up. Thirty-three patients (54\%) in the ADR group had preserved motion ( $\geq 5^{\circ}$ mobility in flexion and extension) at the operated cervical level, while 15 ADRs (25\%) 

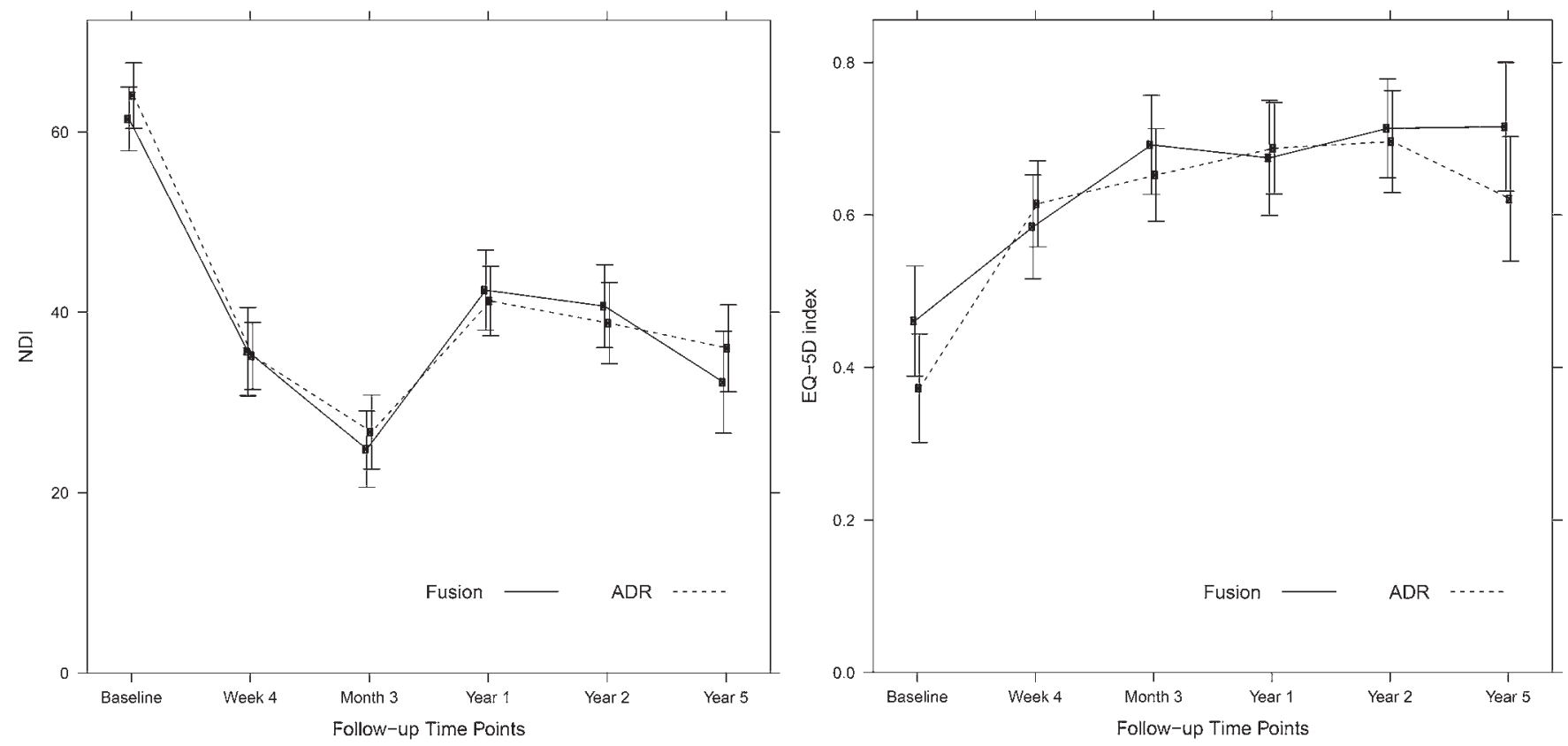

FIG. 2. Imputed data, ITT analysis of ADR versus fusion. Graphs showing the mean values of the NDI (left) and the EQ-5D (right) at each time point for each group. Error bars are $95 \%$ Cls.

were spontaneously fused. The distribution of $\mathrm{HO}$ grades was: grade 0 (none) $=5(8 \%)$, grade $1=1(2 \%)$, grade $2=$ $14(24 \%)$, grade $3=24$ (41\%), and grade 4 (spontaneous fusion $)=15(25 \%)$. Men had $0.9(95 \%$ CI 0.4-1.5) grades higher HO than women $(\mathrm{p}=0.001)$.

Facet arthropathy progressed 0.5 grades in 5 years $(\mathrm{p}<0.001)$ after insertion of the ADR. Before surgery, $61 \%$ had no facet arthropathy compared with $39 \%$ after 5 years (Table 5). However, 5-year MRI was missing in 31 patients, and in 5 patients MR images were not readable because of artifacts or insufficient quality.

\section{Incidence of CASP and RASP}

There were 5 patients in each group with secondary surgery because of severe CASP ( $\mathrm{p}=0.74)$. In addition, $16 / 67$ patients $(24 \%)$ had mild CASP in the ADR group compared with 10/51 (20\%) in the fusion group. Forty (62\%) of 64 patients in the ADR group had no change in RASP 5 years after surgery compared with $21 / 48(44 \%)$ in the fusion group. There were no patients in either group with RASP grade 5.

\section{Discussion}

Our randomized superiority clinical trial revealed no clinical or radiological benefits 5 years postsurgery in ADR compared with fusion surgery, as both groups halved their NDI scores. The ADR group, however, experienced more secondary surgery in women and 1 in 4 patients were spontaneously fused. ADR surgery did not prevent progression of CASP, one of the main arguments for the use of this device.

The finding that patient satisfaction did not differ between the ADR and fusion groups is consistent with previ-

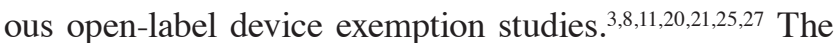
only double-blinded RCT, however, displayed higher NDI scores and more arm pain in the arthroplasty group after 2 years. ${ }^{34}$

In our study, there were fewer reoperations in the fusion group than in the ADR group and the incidence of nonunion was low. Our results contradict other large RCTs with a 5-year follow-up, 3,8 i.e., they reported a higher frequency of secondary surgery in the control group compared with the ADR group, mostly because of nonunion. The difference between our study and others may be explained by surgical technique. We used iliac crest autografts, whereas the IDE studies used allografts, either cut by the surgeon or commercially prepared. Compared with autografts, more dysphagia, ${ }^{4}$ delayed union, ${ }^{32}$ nonunion, ${ }^{1,10}$ and higher pain scores ${ }^{15}$ occur after surgery with allografts.

In contrast, because of ADR loosening or subsidence, our study had a high incidence of reoperations, with bone loss of mostly the upper vertebra on the index level. Consistent with previous reports, the affected patients were mostly women. ${ }^{11}$ An explanation for the sex difference can be anatomical and lack of bone support (men have larger vertebras with higher bone density). The patients were not screened for osteoporosis, and patients with long-term steroidal or nonsteroidal use were not excluded preoperatively, which might have had an impact on the loosening rates. Sex was not identified a priori as a potential independent predictor but the differences between men and women were too clear to be ignored, even though this analysis must be interpreted as a post hoc analysis.

The incidence of HO in our study was higher than that reported in the IDE trials ${ }^{25}$ but similar to the NORCAT (Norwegian Cervical Arthroplasty Trial) reports and other European studies. ${ }^{33}$ The strong tendency toward HO in 

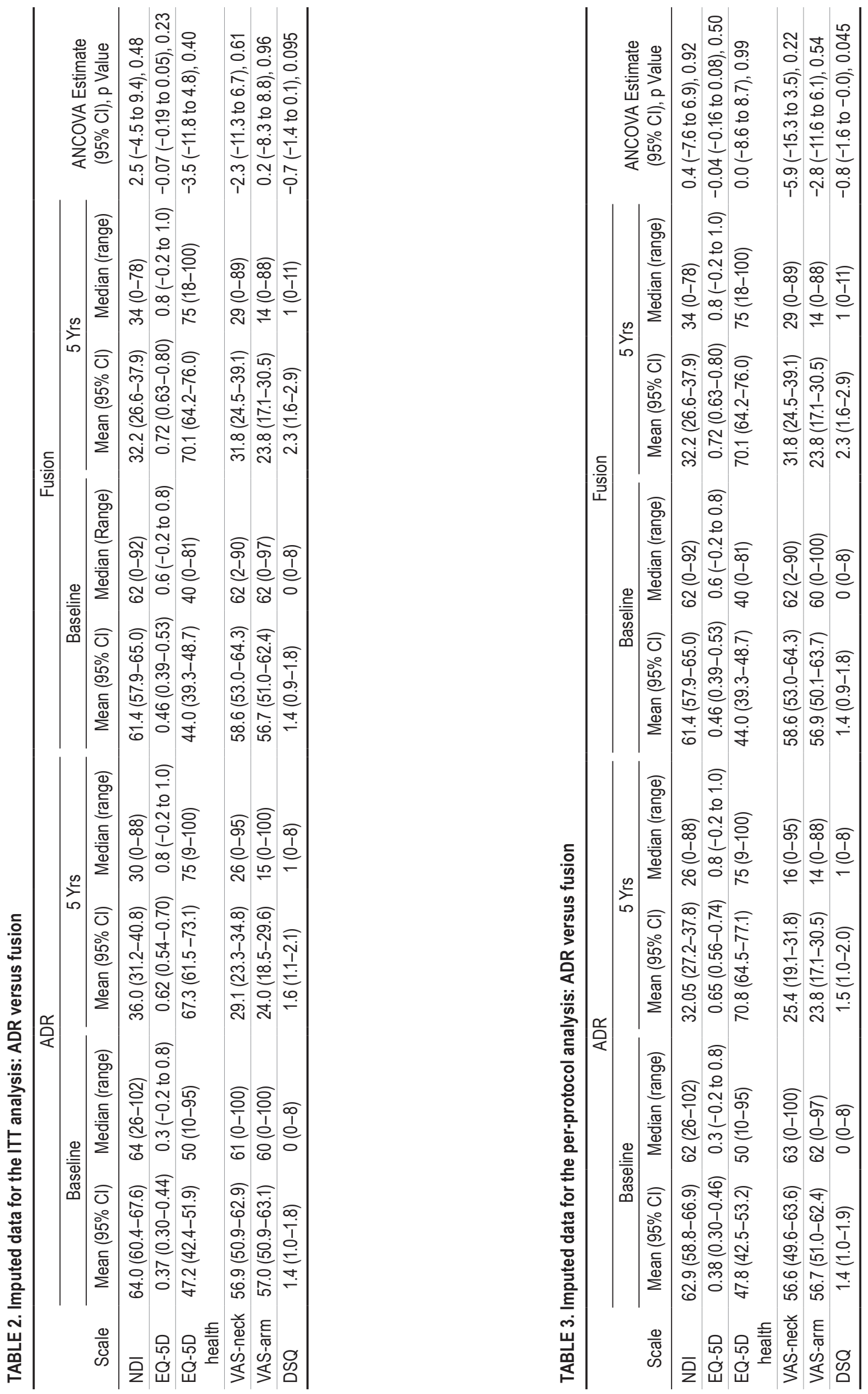


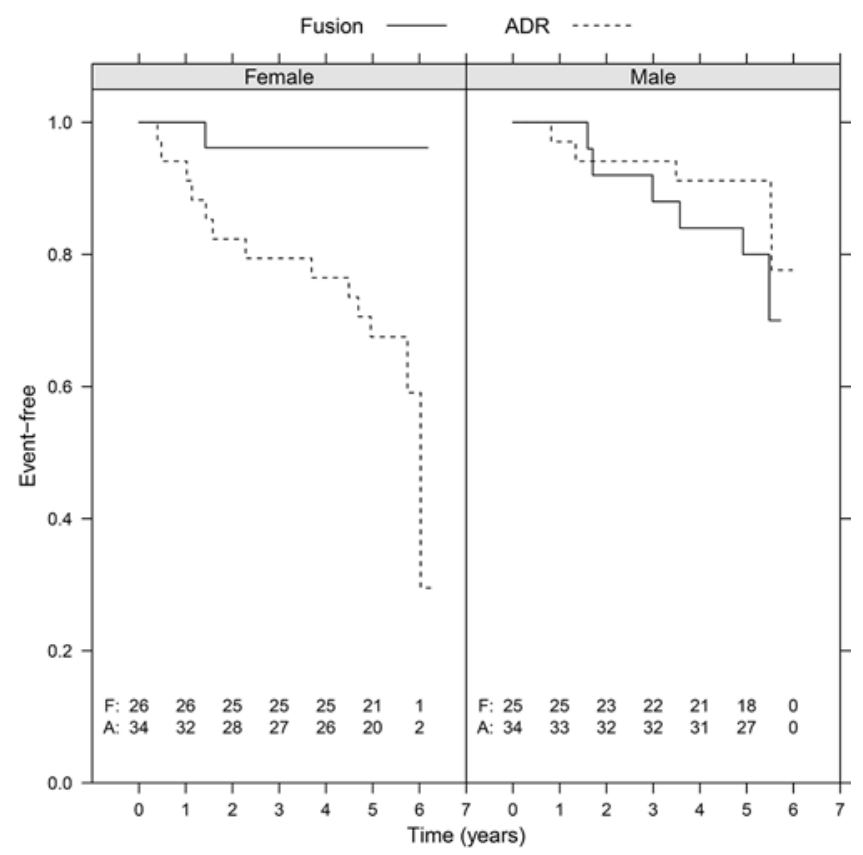

FIG. 3. Kaplan-Meier plot for reoperations stratified by sex.

male patients stabilized the index level and the spontaneously fused patients were pain-free and satisfied with the treatment.

The ADR replaces the disc without interference of the facet joints. Thus, preserved motion on the index level means preserved motion in the facet joints. In our study, facet arthropathy progressed in the ADR group, which could be due to intrinsic age-related changes in the joint. No difference between groups in neck pain could be detected but further long-term studies are needed to determine whether progression of facet arthropathy due to preserved motion will become clinically important.

The presence of ASP was similar in both groups. Although we recognize that longer follow-up durations for ASP symptoms and MRI are necessary, we conclude that the higher incidence of degenerative changes in the fusion group on the adjacent segment on MRI alone, without the

TABLE 4. Reoperations in women and men for the ADR and fusion groups

\begin{tabular}{lcccccc}
\hline & \multicolumn{2}{c}{ ADR } & & \multicolumn{2}{c}{ Fusion } \\
\cline { 2 - 3 } \cline { 5 - 6 } Reason for Reoperation & Women & Men & & Women & Men \\
\hline Loosening \& subsidence & 10 & 4 & & - & - \\
\hline ASP & 6 & - & & 1 & 4 \\
\hline Root canal stenosis & 1 & - & & - & 1 \\
\hline Pseudarthrosis & - & - & & - & 2 \\
\hline Total patients & 13 & 4 & & 1 & 6 \\
\hline
\end{tabular}

There are more reoperations than patients because 2 patients underwent reoperations for both loosening and ASP. In addition, 2 patients underwent a third operation, of whom 1 was reoperated on the third time for both loosening and ASP.
TABLE 5. Prevalence of facet arthropathy and the 5-level grading system

\begin{tabular}{lrrrrrr}
\hline \multirow{2}{*}{$\begin{array}{c}\text { Facet Arthropathy } \\
\text { Grade }\end{array}$} & \multicolumn{5}{c}{ Facet Arthropathy Grade } & \\
\cline { 2 - 6 } & 0 & 1 & 2 & 3 & 4 & Total \\
\hline 0 & 25 & 4 & 8 & 2 & 0 & 39 \\
\hline 1 & 0 & 11 & 3 & 0 & 0 & 14 \\
\hline 2 & 0 & 0 & 4 & 2 & 1 & 7 \\
\hline 3 & 0 & 0 & 0 & 4 & 0 & 4 \\
\hline 4 & 0 & 0 & 0 & 0 & 0 & 0 \\
\hline Total & 25 & 15 & 15 & 8 & 1 & 64 \\
\hline
\end{tabular}

Cross-tabulation of grades preoperatively (rows) and at 5-year follow-up (columns). Facet arthropathy grades determined using the scale of Walraevens et al. ${ }^{36}$

patients having symptoms, does not justify the use of ADR over fusion.

Our study has several strengths. First, MRI for all patients regardless of whether symptoms were present or not, was included in the 5-year follow-up. Second, the followup rate after 5 years for the primary outcome was $88 \%$ and we used multiple imputations for missing values in the ITT analysis for the primary and secondary outcomes. Third, we used blinded allocation for both patients and surgeons until completion of the decompression phase of the surgical procedure. There are also some limitations to discuss. First, the results from the unconstrained ADR device might not be generalizable to constrained devices. Second, only 3 of 4 patients had adequate MR images at follow-up; however, we find it unlikely that this affected our findings because the lower rate was not device-related. A third limitation is that the MRI machines used in this study lack conformity and the quality of the images varied between different scanners.

\section{Conclusions}

We found no differences in primary or secondary outcomes between the ADR and fusion groups after anterior decompression of cervical radiculopathy at the 5-year follow-up. Notably, preserved motion at the index level did not protect against CASP, and women in the ADR group suffered from significantly more secondary surgeries due to loosening or subsidence.

\section{Acknowledgments}

This study was supported by unrestricted grants from the Stockholm County Council, DePuy Synthes Spine, Uppsala County Council, and Swedish Society of Spinal Surgeons. The terms were set such that the sponsors would not be involved in the study design, the conduct of the trial, data analysis, or interpretation of the results. The sponsors were not involved in the writing of the manuscript and did not read the manuscript before submission. The authors thank the Stockholm Spine Center, Anna Arvidsson, and Eva Gulle for collecting/handling data and always assisting in the study.

\section{References}

1. An HS, Simpson JM, Glover JM, Stephany J: Comparison 
between allograft plus demineralized bone matrix versus autograft in anterior cervical fusion. A prospective multicenter study. Spine (Phila Pa 1976) 20:2211-2216, 1995

2. Anderson PA, Andersson GBJ, Arnold PM, Brodke DS, Brodt ED, Chapman JR, et al: Terminology. Spine (Phila Pa 1976) 37 (22 Suppl):S8-S9, 2012

3. Burkus JK, Haid RW Jr, Traynelis VC, Mummaneni PV: Long-term clinical and radiographic outcomes of cervical disc replacement with the Prestige disc: results from a prospective randomized controlled clinical trial. J Neurosurg Spine 13:308-318, 2010

4. Buttermann GR: Prospective nonrandomized comparison of an allograft with bone morphogenic protein versus an iliaccrest autograft in anterior cervical discectomy and fusion. Spine J 8:426-435, 2008

5. Carreon LY, Glassman SD, Campbell MJ, Anderson PA: Neck Disability Index, short form-36 physical component summary, and pain scales for neck and arm pain: the minimum clinically important difference and substantial clinical benefit after cervical spine fusion. Spine J 10:469-474, 2010

6. Chen J, Wang X, Bai W, Shen X, Yuan W: Prevalence of heterotopic ossification after cervical total disc arthroplasty: a meta-analysis. Eur Spine J 21:674-680, 2012

7. Chin-See-Chong TC, Gadjradj PS, Boelen RJ, Harhangi BS: Current practice of cervical disc arthroplasty: a survey among 383 AOSpine International members. Neurosurg Focus 42(2): $\mathrm{E} 8,2017$

8. Delamarter RB, Zigler J: Five-year reoperation rates, cervical total disc replacement versus fusion, results of a prospective randomized clinical trial. Spine (Phila Pa 1976) 38:711-717, 2013

9. DePuy Spine, Johnson \& Johnson: Discover Surgical Technique. Leeds: DePuy International Ltd, 2009

10. Fischer CR, Cassilly R, Cantor W, Edusei E, Hammouri Q, Errico T: A systematic review of comparative studies on bone graft alternatives for common spine fusion procedures. Eur Spine J 22:1423-1435, 2013

11. Hacker FM, Babcock RM, Hacker RJ: Very late complications of cervical arthroplasty: results of 2 controlled randomized prospective studies from a single investigator site. Spine (Phila Pa 1976) 38:2223-2226, 2013

12. Hilibrand AS, Carlson GD, Palumbo MA, Jones PK, Bohlman HH: Radiculopathy and myelopathy at segments adjacent to the site of a previous anterior cervical arthrodesis. J Bone Joint Surg Am 81:519-528, 1999

13. Kim SW, Limson MA, Kim SB, Arbatin JJF, Chang KY, Park MS, et al: Comparison of radiographic changes after ACDF versus Bryan disc arthroplasty in single and bi-level cases. Eur Spine J 18:218-231, 2009

14. Lee SE, Chung CK, Jahng TA: Early development and progression of heterotopic ossification in cervical total disc replacement. J Neurosurg Spine 16:31-36, 2012

15. Löfgren H, Johannsson V, Olsson T, Ryd L, Levander B: Rigid fusion after Cloward operation for cervical disc disease using autograft, allograft, or xenograft: a randomized study with radiostereometric and clinical follow-up assessment. Spine (Phila Pa 1976) 25:1908-1916, 2000

16. MacDermid JC, Walton DM, Avery S, Blanchard A, Etruw E, McAlpine C, et al: Measurement properties of the neck disability index: a systematic review. J Orthop Sports Phys Ther 39:400-417, 2009

17. MacDowall A, Skeppholm M, Lindhagen L, Robinson Y, Olerud C: Effects of preoperative mental distress versus surgical modality, arthroplasty, or fusion on long-term outcome in patients with cervical radiculopathy. J Neurosurg Spine 29:371-379, 2018

18. MacDowall A, Skeppholm M, Robinson Y, Olerud C: Validation of the visual analog scale in the cervical spine. J Neurosurg Spine 28:227-235, 2018
19. Miyazaki M, Hong SW, Yoon SH, Morishita Y, Wang JC: Reliability of a magnetic resonance imaging-based grading system for cervical intervertebral disc degeneration. J Spinal Disord Tech 21:288-292, 2008

20. Mummaneni PV, Burkus JK, Haid RW, Traynelis VC, Zdeblick TA: Clinical and radiographic analysis of cervical disc arthroplasty compared with allograft fusion: a randomized controlled clinical trial. J Neurosurg Spine 6:198-209, 2007

21. Murrey D, Janssen M, Delamarter R, Goldstein J, Zigler J, Tay B, et al: Results of the prospective, randomized, controlled multicenter Food and Drug Administration investigational device exemption study of the ProDisc-C total disc replacement versus anterior discectomy and fusion for the treatment of 1-level symptomatic cervical disc disease. Spine J 9:275-286, 2009

22. Nesterenko SO, Riley LH III, Skolasky RL: Anterior cervical discectomy and fusion versus cervical disc arthroplasty: current state and trends in treatment for cervical disc pathology. Spine (Phila Pa 1976) 37:1470-1474, 2012

23. Nunley PD, Jawahar A, Cavanaugh DA, Gordon CR, Kerr EJ III, Utter PA: Symptomatic adjacent segment disease after cervical total disc replacement: re-examining the clinical and radiological evidence with established criteria. Spine J 13:5-12, 2013

24. Parker SL, Godil SS, Shau DN, Mendenhall SK, McGirt MJ: Assessment of the minimum clinically important difference in pain, disability, and quality of life after anterior cervical discectomy and fusion: clinical article. J Neurosurg Spine 18:154-160, 2013

25. Phillips FM, Geisler FH, Gilder KM, Reah C, Howell KM, McAfee PC: Long-term outcomes of the US FDA IDE prospective, randomized controlled clinical trial comparing PCM cervical disc arthroplasty with anterior cervical discectomy and fusion. Spine (Phila Pa 1976) 40:674-683, 2015

26. Pool JJ, Ostelo RW, Hoving JL, Bouter LM, de Vet HC: Minimal clinically important change of the Neck Disability Index and the Numerical Rating Scale for patients with neck pain. Spine (Phila Pa 1976) 32:3047-3051, 2007

27. Sasso RC, Anderson PA, Riew KD, Heller JG: Results of cervical arthroplasty compared with anterior discectomy and fusion: four-year clinical outcomes in a prospective, randomized controlled trial. J Bone Joint Surg Am 93:1684-1692, 2011

28. Skeppholm M, Ingebro C, Engström T, Olerud C: The Dysphagia Short Questionnaire: an instrument for evaluation of dysphagia: a validation study with 12 months' follow-up after anterior cervical spine surgery. Spine (Phila Pa 1976) 37:996-1002, 2012

29. Skeppholm M, Lindgren L, Henriques T, Vavruch L, Löfgren $\mathrm{H}$, Olerud C: The Discover artificial disc replacement versus fusion in cervical radiculopathy-a randomized controlled outcome trial with 2-year follow-up. Spine J 15:1284-1294, 2015

30. Smith GW, Robinson RA: The treatment of certain cervicalspine disorders by anterior removal of the intervertebral disc and interbody fusion. J Bone Joint Surg Am 40-A:607-624, 1958

31. Strömqvist B, Fritzell P, Hägg O, Jönsson B: The Swedish Spine Register: development, design and utility. Eur Spine J 18 (Suppl 3):294-304, 2009

32. Suchomel P, Barsa P, Buchvald P, Svobodnik A, Vanickova E: Autologous versus allogenic bone grafts in instrumented anterior cervical discectomy and fusion: a prospective study with respect to bone union pattern. Eur Spine J 13:510-515, 2004

33. Suchomel P, Jurák L, Benes V III, Brabec R, Bradác O, Elgawhary S: Clinical results and development of heterotopic ossification in total cervical disc replacement during a 4-year follow-up. Eur Spine J 19:307-315, 2010 
34. Sundseth J, Fredriksli OA, Kolstad F, Johnsen LG, Pripp AH, Andresen H, et al: The Norwegian Cervical Arthroplasty Trial (NORCAT): 2-year clinical outcome after single-level cervical arthroplasty versus fusion - a prospective, singleblinded, randomized, controlled multicenter study. Eur Spine J 26:1225-1235, 2017

35. Tauchi R, Tsuji T, Cahill PJ, Flynn JM, Flynn JM, Glotzbecker M, et al: Reliability analysis of Cobb angle measurements of congenital scoliosis using x-ray and 3D-CT images. Eur J Orthop Surg Traumatol 26:53-57, 2016

36. Walraevens J, Liu B, Meersschaert J, Demaerel P, Delye H, Depreitere B, et al: Qualitative and quantitative assessment of degeneration of cervical intervertebral discs and facet joints. Eur Spine J 18:358-369, 2009 (Erratum in Eur Spine J 18:370, 2009)

37. White IR, Royston P, Wood AM: Multiple imputation using chained equations: Issues and guidance for practice. Stat Med 30:377-399, 2011

38. Yi S, Kim KN, Yang MS, Yang JW, Kim H, Ha Y, et al: Difference in occurrence of heterotopic ossification according to prosthesis type in the cervical artificial disc replacement. Spine (Phila Pa 1976) 35:1556-1561, 2010

39. Young IA, Cleland JA, Michener LA, Brown C: Reliability, construct validity, and responsiveness of the neck disability index, patient-specific functional scale, and numeric pain rating scale in patients with cervical radiculopathy. Am J Phys Med Rehabil 89:831-839, 2010

40. Zigmond AS, Snaith RP: The hospital anxiety and depression scale. Acta Psychiatr Scand 67:361-370, 1983

\section{Disclosures}

DePuy Synthes Spine provided an unrestricted grant for this study. Dr. MacDowall reports being on the board of the Swedish Society of Spinal Surgeons. Dr. Skeppholm reports being a paid speaker for DePuy Synthes Spine. Dr. Robinson reports being on the speaker's bureau and/or giving paid presentations for AOSpine, DePuy Synthes Spine, and Medtronic; and being on the board of the Cervical Spine Research Society (European Section) and AOSpine. Dr. Löfgren reports giving paid lectures for DePuy Synthes Spine. Dr. Olerud reports being on the speaker's bureau for Anatomica, AOSpine, DePuy Synthes, and Medtronic; receiving clinical or research support for the study from Depuy Synthes; and being on the board of the Cervical Spine Research Society (European Section).

\section{Author Contributions}

Conception and design: MacDowall, Olerud. Acquisition of data: MacDowall, Löfgren, Olerud. Analysis and interpretation of data: MacDowall, Canto Moreira, Marques. Drafting the article: MacDowall. Critically revising the article: Skeppholm, Robinson, Michaëlsson, Olerud. Reviewed submitted version of manuscript: Michaëlsson, Olerud. Approved the final version of the manuscript on behalf of all authors: MacDowall. Statistical analysis: Lindhagen. Administrative/technical/material support: Canto Moreira, Marques, Löfgren, Olerud. Study supervision: Skeppholm, Robinson, Olerud.

\section{Supplemental Information \\ Previous Presentations}

Portions of this work were presented in abstract form at the Cervical Spine Research Society's 33th Annual Meeting in Salzburg, Austria, May 24-26, 2017.

\section{Correspondence}

Anna MacDowall: Uppsala University, Uppsala, Sweden. anna. macdowall@surgsci.uu.se. 